\title{
Neue LED-Aushärtungslampen
}

D elo nutzte die diesjährige Hannover Messe, um zwei neue LED-Aushärtungslampen zum einfachen Aushärten photoinitiierter Klebstoffe vorzustellen.

So steht jetzt mit Delolux 202 / 400 ein rechteckiges Modell mit einer Belichtungsstrecke von 200 mm zur Verfügung, das kurze Taktzeiten und damit eine hocheffiziente Klebstoffaushärtung in linearen Produktionsanlagen ermöglicht. Der kompakte Lampenkopf bietet dabei aufgrund seiner innovativen Optik auf der gesamten Belichtungsstrecke eine homogene Intensitätsverteilung.

Ebenfalls neu ist der LED-Punktstrahler Delolux 50 / 365 x4, der bei nur minimal größerem Außendurchmesser des Lampenkopfes eine deutlich gesteigerte Belichtungsfläche von über 100mm2 und eine höhere Intensität gegenüber den bisherigen Delolux 50 Lampenköpfen bietet.

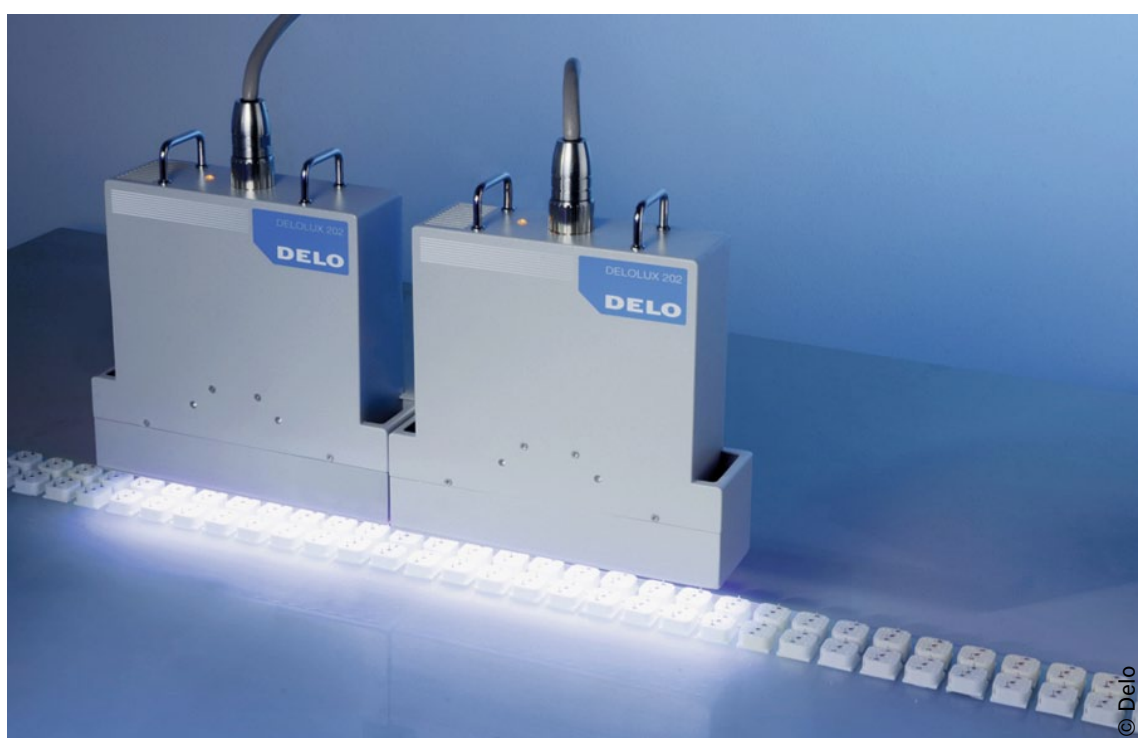

Dieser Flächenstrahler verkürzt die Taktzeiten in der Produktion.

Zudem wurden in Hannover optisch klare Klebstoffe für Display-Verklebungen vorgestellt, die Reflexionen auf dem Display

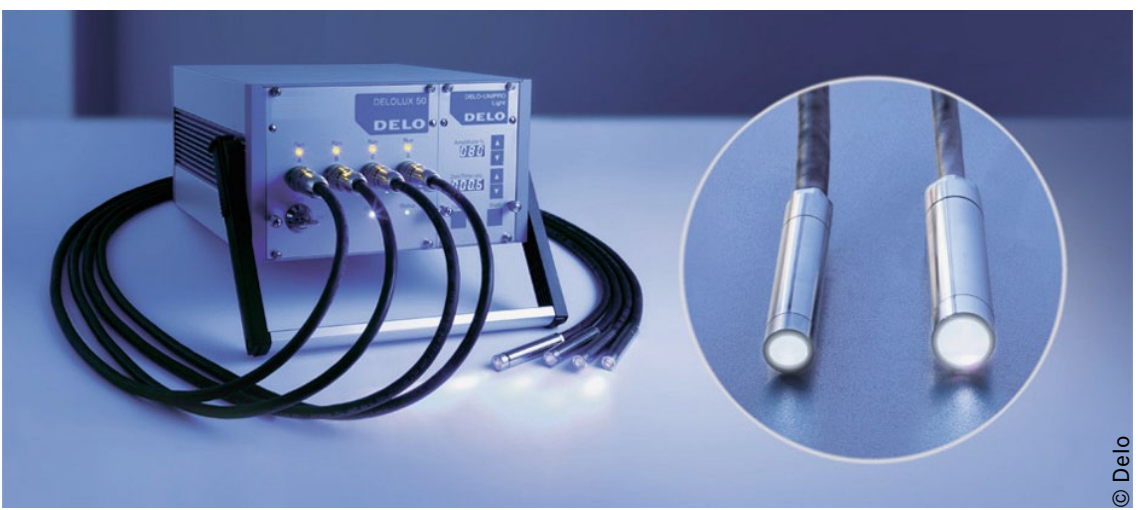

Dieser Flächenstrahler verkürzt die Taktzeiten in der Produktion.

\section{Zielgenaue Infrarot-Kalibratoren}

Diventis ie von CiK Solutions entwickelten Präzisions-Infrarot-Kalibratoren 4180 und 4181 der Serie Fluke zum Kalibrieren von Infrarot-Thermometern sowie Wärmebildkameras zeichnen sich durch ihre einfache Handhabung aus. Sie empfehlen sich sowohl für Anwendungen im Labor als auch in der Werkstatt oder im Feld. Zum Lieferumfang des Geräts gehören die zertifizierte Kalibrierung durch ein international anerkanntes Temperaturkalibrierlabor, eingebaute Musterkalibrierverfahren für Fluke Thermometer und alles, was benötigt wird, um präzise Kalibrierungen von Infrarot-Thermometern im Temperaturbereich von $-15^{\circ} \mathrm{C}$ bis $+500{ }^{\circ} \mathrm{C}$ durchzuführen.

Weitere Infos: CiK Solutions GmbH, info@ cik-solutions.com, www.cik-solutions.com bei Sonneneinwirkung verringern, ebenso wie anisotrop leitfähige Epoxidharze für RFID-Anwendungen, die schnelle und höchst zuverlässige Produktionsabläufe ermöglichen. Gerade bei Anwendungen wie U-Bahn Tickets, Reisepässen oder Plagiatsschutz bei hochwertigen Produkten ist $\mathrm{Zu}$ verlässigkeit ein wichtiges Kriterium.

Weiterhin neu im Angebot sind schnellhärtende Klebstoffe, die in der Optoelektronik Einsatz finden und sich durch geringe Ausgasung, optische Stabilität und einen schnellen Haftungsaufbau auszeichnen.

Weitere Infos: www.delo.de

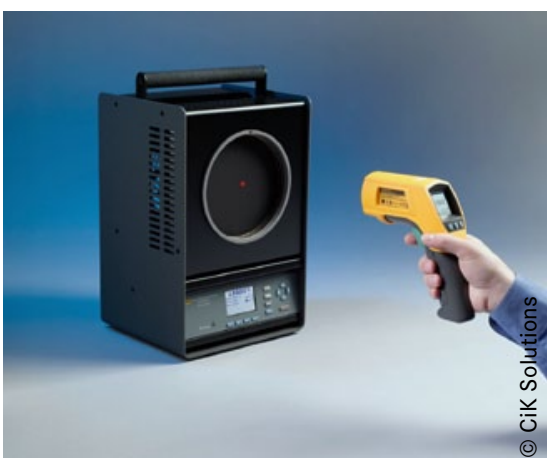

Dieser Infrarot-Kalibrator zeichnet sich durch seine einfache Handhabung aus. 